\title{
Effect of Oral Contraceptive Pills on Tear Film Status and Intraocular Pressure
}

\author{
Zeeshan Kamil $^{1}$, Qirat Qurban ${ }^{2}$, Khalid Mahmood ${ }^{3}$ \\ ${ }^{1-3}$ Khalid Eye Clinic, Nazimabad, Karachi, Pakistan
}

\begin{abstract}
Purpose: To find out the effect of oral contraceptive pills on tear film and intraocular pressure of women of reproductive age group.
\end{abstract}

Study Design: Observational study.

Place and Duration of Study: Khalid Eye clinic, Karachi, from February 2019 to January 2020.

Methods: Eighty females between the 20 to 40 years of age were recruited for this study. They were divided into two groups of forty each. Group A included females using oral contraceptive pills for at least last nine months. Whereas, group B included control group of age matched females not using any contraceptive pills. The study dynamics was explained to all participants and informed consent was obtained. Tear film status was assessed on the basis of Tear film break up time (TBUT) on slit lamp examination and Schirmer strip test 2 (without anesthesia). Intraocular pressures were checked using Goldman Applanation tonometer. Studywas approvedfrom ethical review committee of the hospital.

Results: Mean age was $29.3 \pm 3.27$ years. Tear film break up time was $<7 \pm 1.5 \mathrm{sec}$ in group $A$ and $>10 \pm 1.2$ $\mathrm{sec}$ in group $B$. Schirmer strip test was $\leq 9 \pm 1 \mathrm{~mm}$ of wetting in group $A$ and $\geq 13 \pm 1 \mathrm{~mm}$ of wetting in group $B$. Mean intraocular pressure was $17 \pm 2 \mathrm{mmHg}$ in group $A$ whereas $13 \pm 2 \mathrm{mmHg}$ in group $B$. Grittiness, heaviness and foreign body sensation were more common in group $A$.

Conclusion: Use of oral contraceptive pills has an adverse effect on the tear film status and intraocular pressures.

Key Words: Oral contraceptive pills, Tear film, TBUT, Schirmer's test, Intraocular pressure.

How to Cite this Article: Kamil Z, Qurban Q, Mahmood K. Effect of Oral Contraceptive Pills on Tear Film Status and Intraocular Pressure. Pak J Ophthalmol. 2021, 37 (2): 152-155.

Doi: http://doi.org/10.36351/pjo.v37i2.1069

\section{INTRODUCTION}

Oral contraceptives pills (OCP) are known to be one of the most common, safest and efficient ways of birth control among the females of reproductive age group. With the highest fertility rate among adolescent

Correspondence: Zeeshan Kamil

Khalid Eye Clinic Nazimabad, Karachi, Pakistan

Email: dr.zeeshankamil@yahoo.com

Received: May 20, 2020

Accepted: January 22, 2021 females of Pakistan, along with a high prevalence of home births, the need for using birth control such as OCPs has become pivotal to avoid unplanned pregnancies. ${ }^{1}$

OCPs are comprised of estrogen and progesterone and like any pharmaceutical drug have its own sets of pros and cons including some significant adverse effects on the physiology and pathophysiology of certain ocular tissues. Rocha described the presence of estrogen and progesterone receptors on the lacrimal gland, meibomian gland, lid, palpebral and bulbar conjunctivae, cornea, uveal body, lens, and retina of humans. ${ }^{2}$ This observation lead to the belief that 
females of the reproductive age who use OCPs are at risk of developing complications pertaining to the ocular surface, anterior segment, lens opacities as well as posterior segment (retinal neuro-ophthalmologic or vascular complications owing to thromboembolic events). ${ }^{3}$

Despite the general fact that estrogen reduces lipid secretion and decreases the size of sebaceous glands ${ }^{4}$ few studies have been done to evaluate this relationship. ${ }^{5,6}$ Studies have postulated that using OCPs result in dry eyes owing to the estrogen and progesterone affecting the secretion of lacrimal and meibomian glands ${ }^{7}$ but Sullivan reported that using hormone containing contraceptives, improved the quality and the production of the tear film status. ${ }^{8}$ On the other hand, no significant difference was observed in ocular surface characteristics and tear film status of young women receiving oral contraceptive, in a study done by Tomlinson. ${ }^{9}$ In addition to dry eyes, recently it has been found that both estrogen and progesterone affect the aqueous outflow and thereby regulates the intraocular pressure (IOP). The exact mechanism causing such changes in IOP is yet to be discovered. This indicated that glaucoma may be considered as a component of the risk profile for a patient on oral contraceptive pills, in concert with other existing risk factors. ${ }^{10}$

This study was carried out to find out the effect of oral contraceptive pills on tear film and intraocular pressure of women of reproductive age group of Pakistan.

\section{METHODS}

This study was conducted at Khalid Eye clinic, Karachi, from February 2019 to January 2020 and recruited eighty females between 20 to 40 years of age. Inclusion criteria comprised of women between the ages of 20 to 40 years using oral contraceptive pills for at least since the last nine months, whereas the exclusion criteria included pregnant patients, menopausal women and those who previously underwent any surgery as well as those women having any presence of systemic disease or using systemic medication. Females with ocular surgery, contact lens use, chronic topical medication, laser treatment, chemical injury, blepharitis and any other obvious ocular disorderwere also excluded. They were divided into two groups of forty each. Group A included females using oral contraceptive pills for the last nine months, whereas, group B included control group of females not using any contraceptive pills. The patients of both the groups were demographically matched. The study dynamics was explained to all patients and informed consent was obtained. Study approval was obtained from ethical review committee. A thorough history including personal information, gynecological history, medicine use and duration of hormonal contraceptive was taken from each patient along with presence of or complain of any ocular problem. Comprehensive ocular examination was performed in the OPD to rule out the presence of ocular surface and anterior segment abnormality. The tear film status was assessed in each patienton the basis of Tear film break up time (TBUT) on slit lamp examination and Schirmer strip test 2 (without anesthesia). Intraocular pressure measurement was done with Goldman Applanation tonometry. Schirmer's strip test 2 (without anesthesia) was performed using Whatmann filter paper 41 which was gently placed at the intersection of middle and outer two thirds of the lower lid taking care not to tap cornea or the eye lashes. Patients were advised to look up and blink normally or close the eyes as per their convenience. The paper was removed after five minutes and reading was documented from bent portion of the paper in millimeters. Readings less than $10 \mathrm{~mm}$ after $5 \mathrm{~min}$ was considered as abnormal. Tear film break up time (TBUT) was measured using fluorescein dye drop into the cul-de-sac and tear film was observed on slit lamp with cobalt blue light. Patients were asked not to blink and the appearance of the first dry spot over the cornea was observed indicating a break in the continuity of the tear film. The time between the first complete blink and the appearance of the first dry spot was measured. IOP of both eyes were recorded.

\section{RESULTS}

Mean age was $29.3 \pm 3.27$ years. Tear film break up time was $<7 \pm 1.5 \mathrm{sec}$ in group A and $>10 \pm 1.2 \mathrm{sec}$ in group $\mathrm{B}$, whereas Schirmer strip test result was $\leq 9 \pm 1 \mathrm{~mm}$ of wetting in group $\mathrm{A}$ and $\geq 13 \pm 1 \mathrm{~mm}$ of wetting in group B. Mean intraocular pressure was $17 \pm 2 \mathrm{mmHg}$ in group $\mathrm{A}$ whereas $13 \pm 2 \mathrm{mmHg}$ in group B. Complains such as grittiness, heaviness and foreign body sensation were also more common in patients of group A. 


\section{DISCUSSION}

Production of tears in the eyes act as a natural lubrication, nourishment provider and protection against the environmental dust particles, irritants and infections along with the maintenance of a smooth ocular surface. Any imbalance in the tear film status, either due to composition changes, production abnormality or increased evaporation may lead to dry eyes. ${ }^{11}$ Endocrine system has a significant effect on the lacrimal gland, as proved by the presence of receptors for androgens, estrogen and progesterone in the ocular tissues. ${ }^{9,12}$ Recent studies have also supported that owing to the its expression in several ocular tissues, estrogen has a vital protective part in the pathogenesis of glaucoma by having an impact on the regulation of blood flow. ${ }^{13-16}$ However, the amount or method of estrogen release in order to be protective is yet to be defined. Contraceptive pills most commonly work by inhibiting ovulation. ${ }^{17}$

Our results were similar to the observations made by previous studies which reported that oral contraceptive pills in the reproductive age group lead to dry eye syndrome owing to the androgen deficiency caused by the use of oral contraceptive pills. ${ }^{18-21} \mathrm{~A}$ study by Sullivan had a similar observation that androgen insufficiency could be animperative etiological aspect in the pathogenesis of evaporative dry eye in reproductive age women. Despite such findings, the effects of oral contraceptives in pathogenesis of dry eye remain controversial. ${ }^{9}$ A minority of studies has found no association between the androgen levels and tear film status in women. ${ }^{7,22,23}$ This was contradictory to this study since this study did observe a difference in the tear film status of the women of both groups i.e. those using oral contraceptives had a reduced TBUT and Schirmer strip test result as compared to non oral contraceptive pill users.

This study also found an increase in the mean intraocular pressure at $17 \pm 2 \mathrm{mmHg}$ in women of group A using oral contraceptive pills as compared to $13 \pm 2 \mathrm{mmHg}$ in group B women, who were not using any form of contraceptives. This was in accordance with a study performed among oral contraceptive users for three or more years and it was reported that the use of oral contraceptives was associated with raised intraocular pressure. ${ }^{23}$ It was further supported by a study done by Pasquale in whom the researchers established a 25\% amplified risk of developing primary open angle glaucoma among women who were using oral contraceptives for the last five years or more but this was controversial since it could be related to developing an early menopause. ${ }^{24}$ The release of estrogen from the ovaries regulates the menstrual cycle and using oral contraceptive pills results in low estradiol and progesterone levels thereby increasing serum follicle stimulating hormone levels via negative feedback. The blockage of this natural cycle occurs with the use of oral contraceptive pills hence supporting the proposition by previous literature, which describes that estrogen has a vital protective role in the pathogenesis of glaucoma via regulation of blood flow. ${ }^{14-16}$ In addition to this, none of the oral contraceptive pills have an exact configuration like the physiological hormones during the menstrual cycle, therefore resulting in significant changes in the natural daily, or even hourly, variations in hormone levels and secretion which may be essential in the pathogenesis of glaucomatous diseases. ${ }^{25}$ All the aforementioned findings correlated with this study where the oral contraceptive users reported an increase in the mean intraocular pressure as compared to non users. The emerging evidence of the consequences of female sex hormones on the development of glaucoma suggests that there are unique, gender specific risk factors such as early menopause or use of hormones. Therefore, a better understanding is required for the application and use of oral contraceptives and management of the resulting outcomes.

\section{CONCLUSION}

This study concluded that using oral contraceptive pills has an adverse effect on the tear film status and results in an increase in the intraocular pressure as compared to the non users. However, large scale longer duration studies are required for the affirmation of the possible consequences of using oral contraceptives on the ocular tissues.

\section{Ethical Approval}

The study was approved by the Institutional review board/ Ethical review board. (ERC-23-20).

\section{Conflict of Interest}

Authors declared no conflict of interest. 


\section{REFERENCES}

1. Iftikhar H, Rashid M, Shakoor MU. Decisionmaking for birth location among women in Pakistan: evidence from national survey. BMC Pregnancy Childbirth, 2018; 18: 226. https://doi.org/10.1186/s12884-018-1844-8

2. Rocha EM, Wickham LA, da Silveira LA, Krenzer $\mathbf{K}$, Yu F, Toda I, et al. Identification of androgen receptor protein and 5 a-reducase mRNA in human ocular tissues. Br J Opthalmol. 2000; 84: 76-84.

3. Leff SP. Side-effect of oral contraceptives: occlusion of branch artery of the retina. Bull Sinai Hosp Detroit. 1976; 24 (4): 227-229.

4. Sullivan DA, Yamagami H, Lui M, Schirra F, Liu M, Richards S, et al. Sex steroids, the meibomian gland and evaporative dry eye. Adv Exp Med Biol. 2002; 506 (Pt A): 389-399.

5. Frankel S, Ellis P. Effect of oral contraceptives on tear production. Ann Ophthalmol. 1978: 1585-1588.

6. Tomlinson A, Pearce EI, Simmons PA, Blades K. Effect of oral contraceptives on tear physiology. Ophthalmic Physiol Opt. 2001; 21 (1): 9-16.

7. Schaumberg DA, Buring JE, Sullivan DA, Dana MR. Hormone replacement therapy and dry eye syndrome. J Am Med Assoc. 2001; 286: 2114-2119.

8. Sullivan DA, Wickham LA, Rocha EM, Kelleher RS, Silveira LA, Toda I. Influence of gender, sex steroid hormones and the hypothalamic - pituitary axis on the structure and function of the lacrimal gland. Adv Exp Med Biol. 1998; 438: 11-42.

9. Treister G, Mannor S. Intraocular pressure and outflow facility. Effect of estrogen and combined estrogen-progestin treatment in normal human eyes. Arch Ophthalmol. 1970; 83: 311-318.

10. Gupta PD. Pathophysiology of lacrimal gland in old age. W J Med Sci. 2006; 1: 1-8.

11. Coles N, Lubkin V, Kramer P, Weinstein B, Southern L, Vitter J. Hormonal analysis of tears, saliva, and serum from normals and postmenopausal dry eyes. Invest Ophthalmol Vis Sci. 1988; 29: 48-52.

12. Munaut C, Lambert V, Noël A, Frankenne F, Deprez M, Foidart JM, et al. Presence of oestrogen receptor type beta in human retina. $\mathrm{Br} \mathrm{J}$ Ophthalmol. 2001; 85 (7): 877-882.

13. Wang SB, Hu KM, Seamon KJ, Mani V, Chen Y, Gronert K. Estrogen negatively regulates epithelial wound healing and protective lipid mediator circuits in the cornea. FASEB J. 2012; 26 (4): 1506-1516.

14. Kirker MR, Gallagher KM, Witt-Enderby PA, Davis VL. High affinity nuclear and nongenomic estradiol binding sites in the human and mouse lens. Exp Eye Res. 2013; 112: 1-9.
15. Schmidl D, Schmetterer L, Garhöfer G, PopaCherecheanu A. Gender Differences in Ocular Blood Flow. Curr Eye Res. 2014: 1-12.

16. Christin-Maitre S. History of oral contraceptive drug and their use worldwide. Best Pract Res Clin Endocrinol Metab. 2013; 27 (1): 3-12.

17. Nanavaty MA, Long M, Malhotra R. Transdermal androgen patches in evaporate dry eye syndrome with androgen deficiency: A pilot study. Br J Ophthalmol. 2014; 98: 567-569.

18. Chen SP, Massaro-Giordano G, Pistilli M, Schreiber CA, Bunya VY. Tear osmolarity and dry eye symptoms in women using oral contraception and contact lenses. Cornea, 2013; 32 (4): 423-428.

19. Azcarate PM, Venincasa VD, Feuer W, Stanczyk F, Schally AV, Galor A. Androgen deficiency and dry eye syndrome in the aging male. Invest Ophthalmol Vis Sci. 2014; 55: 5046-5053.

20. Ding J, Sullivan DA. Aging and dry eye disease. Exp Gerontol. 2012; 47: 483-490.

21. Malik TG, Nadeem H, Ayesha E, Alam R. Effect of Short-term Use of Oral Contraceptive Pills on Intraocular Pressure. Pak J Ophthalmol. 2019; 35 (3): 184-187.

22. Burkman R, Bell C, Serfaty D. The evolution of combined oral contraception: Improving the risk to benefit ratio. Contraception, 2011; 84 (1): 19-34.

23. Wang Y, Caitlin K, Diego B, Travis P, Rebecca C, Sophia W, et al. Oral Contraceptive Use and Prevalence of Self-Reported Glaucoma or Ocular Hypertension in the United States. Ophthalmology, 2016; 123 (4): 729-736. Doi:10.1016/j.ophtha.2015.11.029.

24. Pasquale LR, Kang JH. Female reproductive factors and primary open-angle glaucoma in the Nurses' Health Study. Eye (Lond). 2011; 25 (5):633-641.

25. Ahn RS, Choi JH, Choi BC, Kim JH, Lee SH, Sung SS. Cortisol, estradiol-17 $\beta$, and progesterone secretion within the first hour after awakening in women with regular menstrual cycles. J Endocrinol. 2011; 211 (3): 285-295.

\section{Authors' Designation and Contribution}

Zeeshan Kamil; Consultant Ophthalmologist: Examiner, Manuscript writer, final review.

Qirat Qurban; Consultant Ophthalmologist: Data collection, Manuscript writer, final review.

Khalid Mahmood; Consultant Ophthalmologist: Helped in data collection, final review. 